COMMENT

https://doi.org/10.1057/s41599-019-0260-7

\title{
Reconciling material cultures in archaeology with genetic data requires robust cultural evolutionary taxonomies
}

Felix Riede ${ }^{1}$, Christian Hoggard ${ }^{1} \&$ Stephen Shennan ${ }^{2}$

\begin{abstract}
The analysis of ancient genomes is having a major impact on archaeological interpretations. Yet, the methodological divide between these disciplines is substantial. Fundamentally, there is an urgent need to reconcile archaeological and genetic taxonomies. However, traditional archaeological taxonomies are problematic because they are epistemologically weak and often laden with undue assumptions about past ethnicity and demography-they are a hindrance rather than a help in such a reconciliation. Eisenmann and colleagues have recently tackled this issue, offering a palette of potential solutions that circumvents traditional archaeological culture labels. We welcome renewed attention to nomenclature but take issue with such recent work that favours systems of taxonomic assignment for genomic groups that either do not include archaeological information at all or retain traditional cultural taxonomic categories. While superficially pragmatic, these administrative solutions do not address the substantive issues that the topic raises. We here present the argument that the only analytically viable solution to aligning genetic and cultural nomenclature is to conceptualise material culture as underwritten by a system of information transmission across generations that has similar structural properties to the genetic system of information transmission. This alignment facilitates the use of similar analytical protocols and hence allows for a true parallel analysis. Once culture change is also understood as an evolutionary process, a wealth of analytical methods for reconciling archaeological and genetic clusters becomes available.
\end{abstract}

\footnotetext{
${ }^{1}$ Department of Archaeology and Heritage Studies, Aarhus University, Aarhus, Denmark. ${ }^{2}$ Institute of Archaeology, University College London, London, UK. Correspondence and requests for materials should be addressed to F.R. (email: f.riede@cas.au.dk)
} 


\section{Introduction}

nravelling past spatio-temporal patterns and processes of culture change is one of the primary aims of archaeology. Over the last 30 years, genetic analyses have increasingly contributed to this agenda as they promise to disambiguate purely cultural and biological dynamics. A fundamental precondition for recognising such processes is the clear definition of the analytical taxonomic units used for investigation. This entails (i) consistent criteria for their definition and delimitation, the validity of which is established a priori in relation to the questions asked, (ii) a clear taxonomic system into which such archaeological entities can be placed, (iii) agreement on the meaning of the relative ranks within this taxonomic system, and (iv) their meaning within an agreed-upon theoretical framework. These four requirements are essential for conducting comparative and cumulative research at a supra-regional and diachronic scale, and for constructing narratives of deep history.

The definition of archaeological taxonomic units was of great concern to early practitioners, and the typological method (Montelius, 1903) was developed to this end, with evident and explicit inspiration from similar taxonomic efforts in biology (Riede, 2006; Riede, 2010). Taxonomic units-with vernacular labels such as cultures, technocomplexes, groups, industries, traditions or facies-proliferated; these were thought to represent actual past ethnic groups, sometimes implicitly, at other times very much explicitly (Bergsvik, 2003; Clark, 1994; Sackett, 1991; Barton, 1997). The difficulties of inferring group coherence or indeed even ethnicity from archaeological material have reemerged with new urgency in the wake of recent publications such as David Reich's (2018) programmatic monograph on archaeogenetics. Foreshadowed by critical reviews of recent archaeogenetic research (Johannsen et al., 2017; Furholt, 2018; Hofmann, 2015), this publication has engendered immediate responses that argue for a more even-handed integration of genomic and archaeological datasets (Linderholm, 2018; Horsburgh, 2018; Vander Linden, 2018; Klein, 2018; Bandelt, 2018; Kirch, 2018). These responses, however, offer little in the way of concrete advice on how such an integration may be achieved methodologically.

Cognisant of the issue of implied ethnicity and after reviewing the current melange of ad hoc naming conventions, Eisenmann et al. (2018) propose a palette of patently pragmatic rather than polemic solutions that would see genetically-recognised population clusters preferentially named by geography and relative cultural chronology (e.g., C_Europe_LN for the Central-European Late Neolithic). According to Eisenmann et al., such naming conventions offer the advantages of brevity, coherence, accessibility, flexibility, and stability and avoid a simplistic matching of archaeogenomic clusters with archaeological cultures. While useful from the point of view of labelling, however, such taxonomies do not exploit the evidential potential of the archaeological record in relation to past demography. We see the aim of archaeological analysis to be the tracking of patterns and processes of cultural transmission, which can subsequently be brought into dialogue with genetic data under the umbrella of dual-inheritance theory (e.g., Shennan, 2011). In this view, spatial and temporal coherence of certain material culture attributes are the result of cultural transmission dynamics within given populations. Hence, a definition of cultural taxa based on attributes that can reasonably be linked to the transmission of craft skills offers a more robust theoretical grounding. Rather than abstaining from creating cultural taxonomies, we therefore suggest that evolutionary approaches provide a way forward that is at once epistemologically and analytically viable and suitably ambitious vis-à-vis the epistemic work that the archaeological record can potentially do. Rather than abandoning cultural labels we suggest that current cultural taxonomies need to be scrutinised and revised before we can reconcile these meaningfully with their archaeogenomic counterparts.

Evolutionary thinking has a long pedigree in archaeology (Shennan, 2002a), and in the last two decades, substantial strides have been made towards a definition of culture as an evolutionary system parallel to other domains of inheritance (i.e., genetic, epigenetic: see Shennan, 2002b, Lipo et al., 2006; Shennan, 2009). In fact, a major boost to definitions of culture as an information transmission system took the form of formal models inspired by population genetics. Known as gene-culture co-evolution models or dual-inheritance theory, these approaches elaborate the point that culture and genetics are linked but must be understood separately and at similar levels of quantitative sophistication (Boyd and Richerson, 1985; Cavalli-Sforza and Feldman, 1981). In the following, we demonstrate the epistemological and methodological differences between traditional definitions of archaeological cultures and evolutionary archaeological definitions thereof. We then show how the evolutionary nomenclatures become amenable to analytical approaches (i.e., phylogenetics and formal modelling) that mirror those used in population genetics and how these hence offer interpretative avenues that deliver substantially higher epistemic dividends. This paper is a comment on recent taxonomic practice offered in the hope of stimulating further productive developments.

\section{Ideational versus materialist definitions of culture-and the role of computational methods}

Archaeologists developed an ideational, essentialist and top-down typological approach in the late $19^{\text {th }}$ and early $20^{\text {th }}$ century, a time when rapid agricultural and industrial development resulted in a massive increase of archaeological finds that needed to be put in order. Archaeological typology was in fact modelled on biological taxonomies as understood at that time (Riede, 2010). However, biology later went through a conceptual revolution that transformed this essentialist understanding of these key analytical units into a materialist and population-focused one (Mayr, 1959). This was then followed by the adoption of computers opening up novel ways of dealing with ever-larger datasets and with this everlarger variation without resorting to the obvious abstraction of idealisation (Hagen, 2003). In turn, this facilitated the development of precisely those phylogenetic methods now used to partition biological variation at different levels (O'Hara, 1997), including the intra-population divisions into clusters now so clearly revealed for past human populations by recent aDNA genomic studies.

In contrast, and despite the efforts of David Clarke (1968) in the 1960s to develop a 'polythetic' definition of archaeological entities, much of archaeology never underwent such a conceptual and methodological overhaul (Lycett and Shennan, 2018). At the time when such a rethinking might have happened, the discipline instead turned towards different concerns (Shennan, 2004; Trigger, 2006). Computers and statistics were slow to make an inroad into the discipline (e.g., Aldenderfer, 2005) and cultural taxonomic studies fell radically our of fashion with the result that culture-historical nomenclatures were largely left unexamined and unrevised (Roberts and Vander Linden, 2011). The current diversity of archaeological taxonomic units and the evident methodological heterogeneity behind their construction and interpretation is a major issue for both later prehistory, as summarised by Eisenmann et al., and also for earlier periods (Clark and Riel-Salvatore, 2006; Sauer and Riede, 2019). In part at least, this heterogeneity is the result of an inertia in the revision of epistemologies and analytical methods when it comes to 
classification and cultural taxonomy (Bisson, 2000), an inertia linked at least in part to the obvious need to communicate within the discipline and to external stakeholders including the public. In addition, many traditional typological units have become reified in heritage databases. Their epistemological status has nonetheless come under close scrutiny and one branch of archaeology has begun to address this issue, evolutionary archaeology. Inspired by the development of gene-culture co-evolutionary models, which view culture as a multi-generational system of information transmission akin to but also different in its details from genetic inheritance (CavalliSforza and Feldman, 1981; Boyd and Richerson, 1985), evolutionary archaeologists have for the last 30 years been adapting both micro-evolutionary (population genetic), as well as macro-evolutionary (phylogenetic) methods to the study of material culture change (Bettinger, 2008; O'Brien and Lyman, 2000; O'Brien, 2008; Shennan, 2009; Shennan, 2008; Lipo et al., 2006; Mace et al., 2005; Shennan, 2002b). Such conceptions of cultural variation are also highly cognisant of not conflating phylogenetic branches with biological or ethnic groups, but instead argue that they can validly be understood as the outcome of past communities of practice (Fig. 1; O'Brien et al., 2008; Collard and Shennan, 2008; Riede, 2011b).

We know from many detailed studies of past technologies which traits are best suited for such analysis and which traits are likely to reflect knowledge and know-how acquired as part of apprenticeship processes involving close interaction between learner and teacher (Jordan, 2015; Stark et al., 2008; Tehrani and Riede, 2008; Tostevin, 2013). Instead of placing archaeological material into preconceived and usually rather static ideal categories, such evolutionary approaches apply phylogenetic techniques and isolation-by-distance modelling (Shennan et al., 2015), among other methods, to empirically investigate taxonomic structure in a given dataset. Such techniques can additionally also provide independent estimates of population contact and mixing, in the future creating archaeologically-based admixture graphs (Pickrell and Pritchard, 2012), which can be tested against genetic data. In addition, such techniques can reveal structured nesting of coherent cultural taxonomic groups and thereby provide robust criteria for differentiating between vernacular categories such as cultures, technocomplexes, groups, industries, traditions or facies that are often, but rarely consistently, understood to represent different levels of cultural differentiation. Such phylogenetically derived groupings can then be understood as past communities of practice tied together by shared transmission histories of cultural traits, i.e., they represent the methodological complement to palaeogenetic clusters that are the result of shared biological transmission histories. In principle, these clusters should then display a degree of spatial and temporal coherence, but spatiotemporal coherence is a result of, rather than a necessary feature for, taxonomic coherence.

\section{Selecting the right proxies for the right questions}

The current wave of archaeogenetic studies is trying to assess past population relationships and the dynamics that produced them using genetic proxies. Similarly, archaeological taxonomies are tools to infer past cultural dynamics. Yet, both spatial and temporal proximity are rather indirect proxies at best for interaction patterns especially under those conditions-rapid culture change, dispersal, migration and population contact-of particular interest to such investigations. Chronology is important but a poor proxy for cultural relatedness because multiple traditions can coexist at any one time. Just as a given population can contain multiple genetic variants, so can their cultural composition be a mixture of many traditions and practices, as has been demonstrated for the Neolithic and Bronze Age Corded Ware and Bell Beaker cultures (Furholt, 2014; Vander Linden, 2016). Spatial proximity is a poor proxy for cultural relatedness because humans can be highly mobile. That said, geographic closeness does play some role in structuring cultural transmission and hence material culture variation but the degree to which this is so must be assessed empirically on a case-by-case basis (Jordan and O'Neill, 2010; Jordan, 2009). The key characteristic in question, cultural evolutionary descent (i.e., historical relatedness), is more robustly

\section{A: Typological thinking}

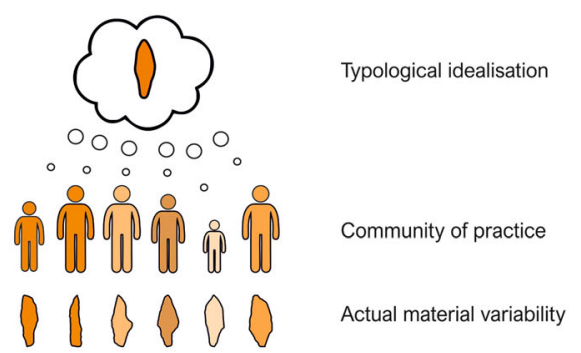

\section{B: Population thinking}

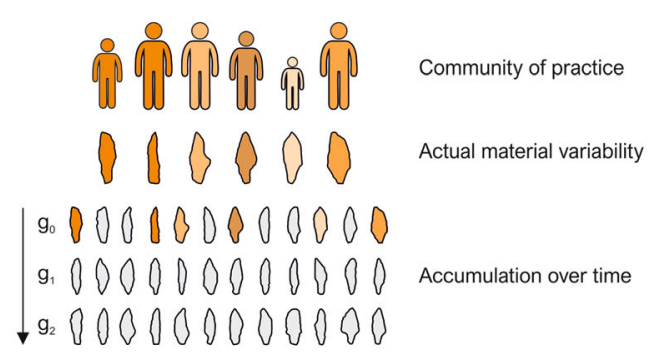

Fig. $1 \mathrm{~A}$ schematic figure outlining the difference between typological thinking and population thinking as implemented in regard to material culture variation. A given population (from which also archaeogenetic samples are taken) is seen as a community of practice (Lave and Wenger, 1991) composed of individuals of different age, sex, ability, access to knowledge and raw materials, here indicated by size and colour differences. Production processes and pedagogical practices in such past communities can sometimes be inferred in great detail (Donahue and Fischer, 2015; Bodu, 1996; Högberg, 2008). The artefacts produced in such communities vary, which is shown here through the outlines of Final Palaeolithic (15,000-11,000 cal BP) large tanged points from the type site of the so-called Bromme culture (Mathiassen, 1946). Panel a shows how within the framework of traditional typological thinking, the typological abstraction is thought of as a somehow idealised shared mental template, here represented by the median shape, which however has no actual empirical representative. Once defined, such idealised types act as reified stand-ins for the communities of practice. In contrast, panel $\mathbf{b}$ shows how in a materialist approach further variation is considered to be introduced over generations ( $g$ ) into the total sample of artefacts (Eerkens and Lipo, 2007), which can subsequently be selected by cultural and natural factors. Here, large samples of artefacts, together with chronological and spatial data facilitate inferences about transmission processes and hence about changing population dynamics 
Table 1 Different broad categories of cultural transmission that produce attendant long-term dynamics of culture change (Hewlett and Cavalli-Sforza, 1986)

\begin{tabular}{|c|c|c|c|c|}
\hline & \multicolumn{4}{|c|}{ Modes of Cultural Transmission } \\
\hline & Vertical & Horizontal & One-to-Many & Many-to-One \\
\hline Transmitter & Parents & Unrelated & Teachers / "masters" & Elders / "masters" \\
\hline Learner & Child & Unrelated & Pupils / "apprentices" & Youths / "apprentices" \\
\hline $\begin{array}{l}\text { Acceptance } \\
\text { of innovation }\end{array}$ & Moderately difficult & Easy & Easy & Very difficult \\
\hline $\begin{array}{l}\text { Cultural variation } \\
\text { between actors }\end{array}$ & High & Can be high & Low & Low \\
\hline $\begin{array}{l}\text { Cultural variation } \\
\text { between groups }\end{array}$ & High & Can be high & Can be high & Low \\
\hline $\begin{array}{c}\text { Tempo of } \\
\text { cultural evolution }\end{array}$ & Slow & Can be rapid & Can be rapid & Slow \\
\hline
\end{tabular}

Evolutionary analyses of material culture can be read according to such a theoretically derived framework

tracked by those traits acquired through social learning in the intimate settings of childhood and apprenticeship (Table 1).

Against the background of their very valuable review, Eisenmann et al. accept a diversity in naming practice and argue that workable nomenclatures must satisfy five key criteria: brevity, coherence, accessibility, flexibility, and stability. Phylogenetically derived cultural clusters do not come with vernacular labels readymade, although particular monophyletic branches occasionally coincide with traditionally-named cultures, whose designations could then, in principle, be transferred so long as the new basis for them was clear (Riede, 2011a). Yet, while names can be important, we consider issues of coherence, accessibility, flexibility, and replicability more critical. While clearly safeguarding against naïve juxtapositions of archaeogenomic and archaeological patterns, we worry that the labelling approach of Eisenmann et al. underutilises the epistemic potential of the archaeological record for shedding light on population-level processes of cultural transmission, mobility and contact. In contrast, computational phylogenetic and network-based methods, including the use of admixture trees, offer a transparent, replicable and case-transferable way to construct statistically validated and hence stable archaeological operational taxonomic units, especially as code-sharing and replicability come to the fore within the discipline (Marwick et al., 2017; Marwick, 2017). Archaeological taxonomies could be constructed using a wide range of material culture datasets, going from relatively simple presence/absence counts of particular object classes in, for instance graves or settlements to two- or three-dimensional object scans taken from key artefacts; we provide an example of such an approach below. The ever-more rapid capture of such digital images and scans would swiftly result in large databases; artefact forms could then be interrogated using, for instance, geometric morphometric approaches (Petř́k et al., 2018; Schillinger et al.,
2016; Serwatka and Riede, 2016; Buchanan et al., 2014) coupled with more traditional trait-based analyses.

Once a solid overview of the existing material culture variation is attained and appropriate analytical protocols are established, adding data derived from newly excavated sites or previously untapped museum archives becomes straightforward. It is interesting to note in this context that archaeologists make widespread use of drawings as a way of conveying artefact characteristics (Lopes, 2009). Many extensive catalogues of such drawings exist. More often than not, it is these drawings rather than the actual objects that then are consumed and absorbed by practitioners when constructing or circumscribing particular cultural units. The digitisation and subsequent computer-aided analysis of such images is now within easy reach.

\section{Computational methods for constructing cultural taxonomies: morphometrics and cultural phylogenetics}

To demonstrate the importance of computational phylogenetic and network-based methods in assessing operational taxonomic units, we present a dendrogram of broadly contemporaneous Final Palaeolithic large tanged points as an example. Based on their size, evaluated against the ballistic requirements of different weapon delivery systems, these most likely all served as dartpoints associated with a spear-thrower propulsion system (Riede, 2009b); in order to avoid confounding factors such as resharpening we include only complete specimens in our analysis. Traditional culture-historical assignments see variants of this artefact class representing local or regional populations, descended from a common ancestor (Sinitsyna, 2002; Szymczak, 1987), most notably the southern Scandinavian Bromme culture (Mathiassen, 1946). To evaluate this quasi-ethnic population division, we construct a dendrogram based on a two-dimensional geometric morphometric methodology, encompassing 226 large 


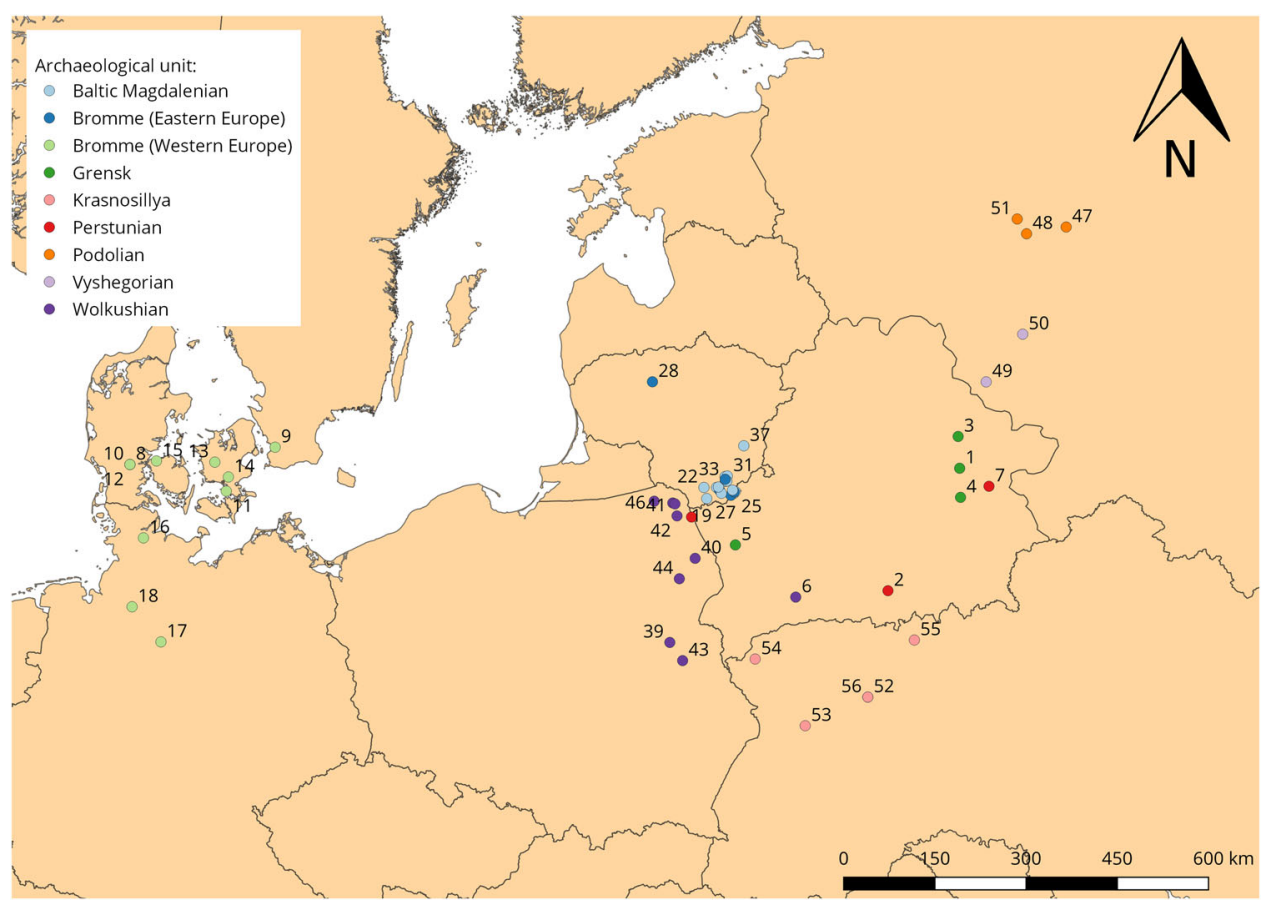

Fig. 2 A map of all sites examined throughout the article $(n=56)$. (1) Baroŭka; (2) Chilczyce; (3) Chvojnaja; (4) Koromka; (5) Krasnasieĺski; (6) Motol; (7) Woronowka; (8) Elemly Sø; (9) Hjarup Mose; (10) Rolykkevej; (11) Rundebakke; (12) Sølystgaard; (13) Bromme; (14) Trollesgave; (15) Bro; (16) Alt Duvenstedt; (17) Dohnsen; (18) Sassenholz; (19) Baltašiškès; (20) Derežnyčia; (21) Duba; (22) Ežerynas; (23) Glūkas; (24) Glyno Pelkè; (25) Gribaša; (26) Kašètos; (27) Katra; (28) Lieporiai; (29) Marcinkonys; (30) Margių; (31) Maskauka; (32) Merkys-Ūla; (33) Mitriškẻs; (34) Rudnia; (35) Varèna; (36) Varẻnė; (37) Vilnius; (38) Burdeniszki; (39) Dziewule-Piaski; (40) Krzemienne; (41) Maćkowa Ruda; (42) Płaska; (43) Stańkowicze; (44) Suraż; (45) Wolkusz; (46) Zusno; (47) Podol; (48) Ust-Tudovka; (49) Anosovo; (50) Vishegore; (51) Tieply NRuchey; (52) Krasnosillya; (53) Lipa; (54) Liutka; (55) Rudnya; (56) Velyky Midsk

Table 2 The dataset used for the dendrogram $\left(n_{\text {total }}=226\right)$

\begin{tabular}{ll}
$\begin{array}{l}\text { Archaeological } \\
\text { taxonomic unit }\end{array}$ & Sample size $(\boldsymbol{n}=)$ \\
\hline Grensk & 55 \\
Bromme (Western Europe) & 49 \\
Baltic Magdalenian & 36 \\
Krasnosillya & 29 \\
Wolkushian & 22 \\
Podolian & 14 \\
Bromme (Eastern Europe) & 9 \\
Vyshegorian & 8 \\
Perstunian & 4 \\
\hline
\end{tabular}

tanged point illustrations from Eastern and Northern Europe (Fig. 2). Illustrations from this geographical region include examples from Belarus, Lithuania, Poland, western Russia and Ukraine; we also include illustrations from the Bromme culture itself (Table 2).

To examine differences between archaeological units through geometric morphometrics, elliptic Fourier analysis (EFA henceforth) was utilised. EFA is a common method of closed-outline shape analysis grounded in the decomposition of closed outlines into an infinite series of repeating trigonometric functions (harmonics). In comparison to other methods of two-dimensional closed-outline methods including coordinate-point eigenshape (Macleod, 1999), Fourier radius variation and Fourier tangent angles (Zahn and Roskies, 1972), and the fitting of polynomial curves (Rogers and Fog, 1989), EFA boasts a number of methodological advantages. One noticeable advantage is that EFA does not require data points to be equal in number, or evenly spaced, allowing more closely-spaced data points on segments of high curvature and artefact complexity (Rohlf and Archie, 1984; Crampton, 2007). As such, EFA is now commonplace in the statistical analysis of archaeological stone tool shapes (e.g., Saragusti et al., 2005; Iovita, 2009; Cardillo, 2010; Iovita et al., 2017; Serwatka, 2015). For more information on the fundamentals and mathematical framework underpinning EFA please refer to Caple et al. (2017).

All illustrations (.png) were first synthesised into one thin-plate spline (.tps) file, common for geometric morphometric analyses. This was performed in tpsUtil v.1.69, with Cartesian coordinates and positions for each image created using the 'Outline object' function in tpsDig2 v.2.27 (Rohlf, 2015). As these outlines do not require the same number of landmarks (given the chosen method of analysis), and in order to capture as much of the original shape as possible, the raw outline was retained. Thus, the tanged points feature an average of 1544 Cartesian coordinates. In standardising all outlines prior to EFA, all specimens were normalised to a common centroid $(0,0)$ and rescaled using their centroid size (Bonhomme et al., 2017).

Normalisation through rotation was unnecessary as this is incorporated through subsequent elliptic fitting. A principal component analysis (PCA) was then conducted on the elliptic Fourier coefficients, with the principal scores used for agglomerative hierarchical cluster analysis (with archaeological taxonomic units for the tanged points displayed). All analyses were performed in the R Environment (R Core Team, 2017), using Momocs v.1.2.9 (Bonhomme et al., 2014). For visualisation of the dendrogram (Fig. 3) the ggtree v.10.5 package was used (Yu et al., 2016). The .tps file, metadata (in .csv format) and R Markdown (d: in .rmd and .html formats), extensively detailing the 


\section{Archaeological unit:}

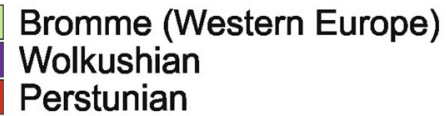

Podolian Vyshegorian Grensk

\section{Bromme (Eastern Europe) Krasnosillya Baltic Magdalenian}

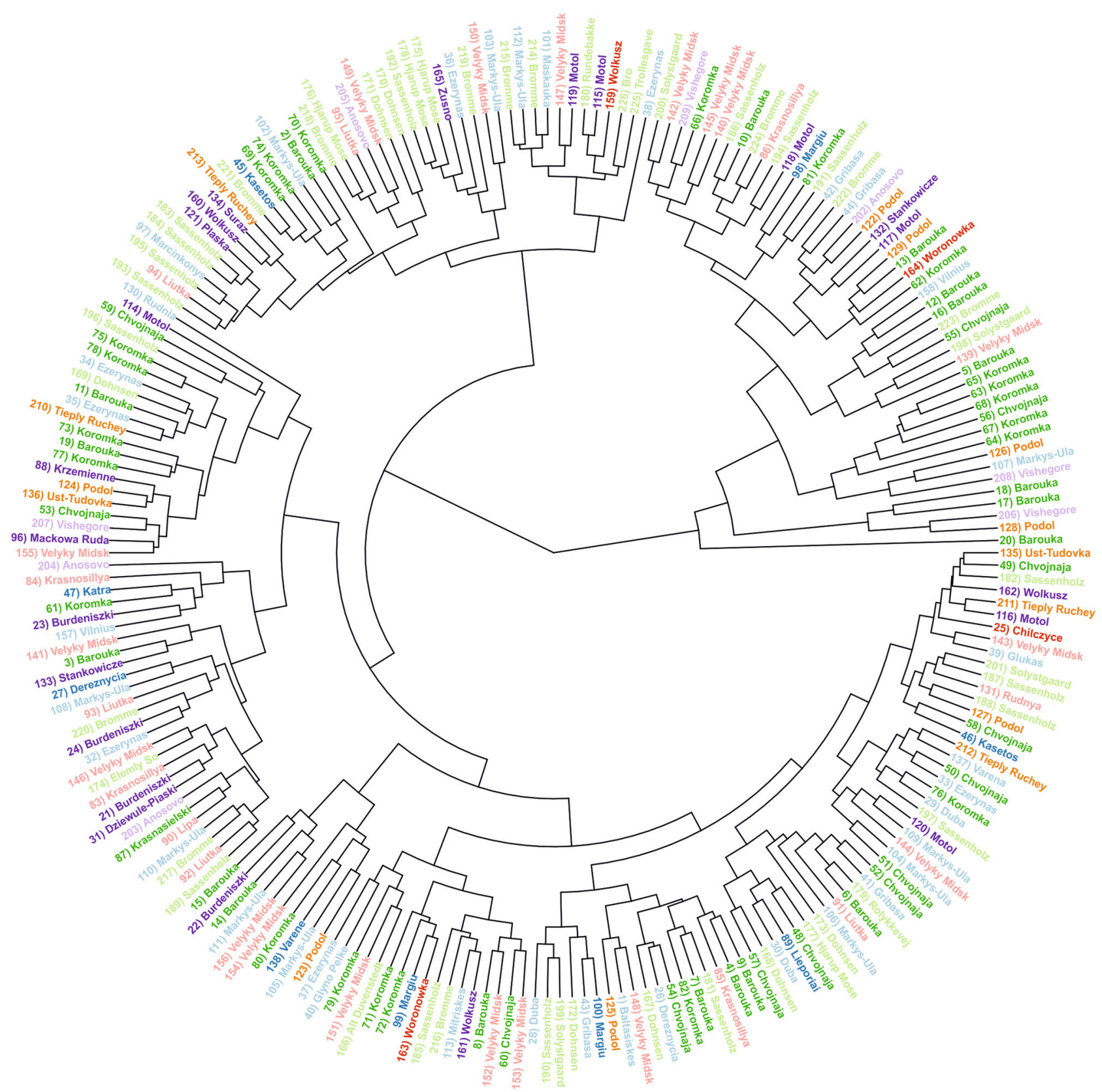

Fig. 3 An example dendrogram of broadly contemporaneous Final Palaeolithic (15,000-11,000 cal BP) unifacial large tanged points from Europe. All these objects are technologically very similar and are often thought to be historically related. Here, they are analysed by their two-dimensional shape variation using geometric morphometric methods. Colours mark traditional typological labelling, reflecting culturehistorical divisions of the material into regional units and sub-units: cultures. Such a tree-building analysis reveals cultural taxonomic structure at different levels without a priori idealisation, but also shows that many traditional units cannot be re-found in this manner. Large numbers of objects can readily be included in the analysis and the placement of each object can be tracked

exploratory procedure in this article, can be found on the Open Science Framework ${ }^{1}$.

By then including dating information and stratigraphy, such dendrograms can be transformed into cladograms and used to infer the cultural evolutionary history of particular communities of practice. The critical result here is, however, that very few of the objects traditionally assigned to different 'cultures' defined by region or presumed affinity show consistent clustering (see Fig. 3). This supports recent critiques of this particular artefact class as a valid cultural diagnostic (Kobusiewicz, 2009; Riede, 2017; Serwatka and Riede, 2016) and demonstrates that traditional definitions of archaeological cultures are ripe for reinvestigation 
using computational methods. Once archaeological groups are defined as operational taxonomic units within a transmission system, they become epistemologically aligned with genetic groups, opening avenues for parallel co-phylogenetic analyses that compare like with like.

\section{The promise of a phylogenetic concept of culture}

In the above, we have sketched out a roadmap for creating robust operational archaeological units that can, in principle, be meaningfully reconciled with archaeogenetics, as well as, incidentally, palaeoenvironmental datasets (Gamble et al., 2005). No ancient genetic analyses matching our Final Palaeolithic case study are available yet and we do admit that archaeology still has some way to go before such analytical definitions of culture become widespread. It is also critical that, whenever possible, multiple artefact classes are used to build cultural evolutionary trees as different objects may be responsive to different transmission pathways (related to age, gender, status, or use context). Also, techniques other than $2 \mathrm{D}$ or $3 \mathrm{D}$ morphometrics can be used, for instance, technological and attribute analysis; this is particularly relevant for lithic strategies which may not provide distinct shapes (and thus cannot be detected through EFA), e.g., blade-blank industries. These challenges aside, the similarities and differences between these cultural lineages-and their associated genetic patterns-would be revealing about societal dynamics. Future analyses aiming at the parallel understanding the diachronic evolution of genetic and cultural frequencies should target those sites that may yield aDNA, as well as directly associated artefact assemblages allowing for a rigorous re-analysis of the artefact material.

In sum, we see little value in replacing traditional cultural but problematic nomenclatures with new ones that do not make fuller use of the epistemic potential of the material at hand. Instead we strongly encourage archaeologists and geneticists together to seize the opportunity provided by parallel revolutions in not just archaeogenetics and in the palaeoenvironmental sciences but also, critically, in computational archaeology to more comprehensively refurbish archaeological taxonomic approaches. The promise of defining archaeological cultures phylogenetically rests not only in the robustness and transparency of the approach but also in bringing archaeological and genetic approaches methodologically closer. Once, but only once, both genetic clustering and material culture clustering are defined phylogenetically, can we explore how to compare the emergent structures in those datasets and the various drift and selection forces acting to produce them, not just qualitatively but quantitatively-and such co-phylogenetic methods are available (Tehrani et al., 2010; Riede, 2009a, Bortolini et al., 2017). Note finally that Marwick and Schmidt (2019) have recently shown how the adoption of new tools is driving substantial scientific advances in archaeology. The impact of purely natural scientific methods such as palaeogenomics on historical disciplines such as archaeology is beyond doubt (Kristiansen, 2014), Marwick and Schmidt demonstrate specifically how quantitative analytical approaches and code sharing also drive such change.

Our concern voiced here, namely to upgrade our treatment of the archaeological evidence in terms of constructing cultural taxonomies is, we believe, fully aligned with the intentions of Eisenmann et al. (2018, p. 10) who have deliberately offered their contribution as a springboard for "further reflection on the topic of naming conventions in archaeogenetics". Unlike many other discussions of the conceived and real challenges in bringing archaeology and palaeogenetics together, our comment is directed primarily at our archaeological colleagues. We hope to have shown here that, rather than simply addressing naming conventions, a conceptually and methodologically forwardlooking avenue for taking archaeogenetics and archaeology into the future lies in a materialist, population-based re-thinking of the archaeological cultures themselves.

Data sharing. Datasets related to this study are available at the OSF repository at (DOI: 10.17605/OSF.IO/VTDF2): https://osf. io/vtdf2/

Received: 11 January 2019 Accepted: 25 April 2019

Published online: 28 May 2019

\section{Notes}

1 Data for "Reconciling material cultures in archaeology with genetic data requires robust cultural evolutionary taxonomies" (Authors: Felix Riede, Christian S. Hoggard and Stephen J. Shennan) (DOI: 10.17605/OSF.IO/VTDF2): https://osf.io/vtdf2/

\section{References}

Aldenderfer M (2005) Statistics for archaeology. In: Maschner HDG, Chippindale C (eds.) Handbook of archaeological methods. Vol. 1. AltaMira Press, Lanham

Bandelt H-J (2018) David Reich's who we are and how we got here: ancient DNA and the new science of the human past. Curr Anthropol 59:659-661

Barton CM (1997) Stone tools, style, and social identity: an evolutionary perspective on the archaeological record. In: Barton CM, Clark GA (eds) Rediscovering Darwin: evolutionary theory in archaeological explanation. American Anthropological Association, Washington, D.C.

Bergsvik KA (2003) Mesolithic ethnicity-too hard to handle. In: Larsson L, Kindgren H, Knutsson K, Loeffler D, Åkerlund A (eds) Mesolithic on the move. Oxbow, Oxford

Bettinger RL (2008) Cultural transmission andarchaeology. In: O'Brien MJ (ed.) Cultural transmission and archaeology: issues and case studies. Society for American Archaeology Press, Washington, D.C.

Bisson MS (2000) Nineteenth century tools for twenty-first century archaeology? Why the Middle Paleolithic Typology of François Bordes Must Be Replaced. J Archaeol Method Th 7:1-48

Bodu P (1996) The Magdalenian hunters of pincevent. Aspects of their behavior. Lithic Technol 21:66-70

Bonhomme V, Forster E, Wallace M, Stillman E, Charles M, Jones G (2017) Identification of inter- and intra-species variation in cereal grains through geometric morphometric analysis, and its resilience under experimental charring. J Archaeol Sci 86:60-67

Bonhomme V, Picq S, Gaucherel C, Claude J (2014) Momocs: outline analysis using R. J Stat Softw 56:1-24

Bortolini E, Pagani L, Crema ER, Sarno S, Barbieri C, Boattini A, Sazzini M, Da Silva SG, Martini G, Metspalu M, Pettener D, Luiselli D, Tehrani JJ (2017) Inferring patterns of folktale diffusion using genomic data. Proc Natl Acad Sci 114:9140

Boyd R, Richerson PJ (1985) Culture and the evolutionary process. University of Chicago Press, Chicago

Buchanan B, O'brien MJ, Collard M (2014) Continent-wide or region-specific? A geometric morphometrics-based assessment of variation in Clovis point shape. Archaeological and Anthropological Sciences 6:145-162

Caple J, Byrd J, Stephan CN (2017) Elliptical fourier analysis: fundamentals, applications, and value for forensic anthropology. International Journal of Legal Medicine 131:1675-1690

Cardillo M (2010) Some applications of geometric morphometrics to archaeology. In: Elewa AMT (ed) Morphometrics for nonmorphometricians. Springer, Berlin/Heidelberg

Cavalli-Sforza LL, Feldman MW (1981) Cultural transmission and evolution: a quantitative approach. Princeton University Press, Princeton

Clark GA (1994) Migration as an explanatory concept in Paleolithic archaeology. J Archaeol Method Th 1:305-343

Clark GA, Riel-Salvatore J (2006) Observations on systematics in paleolithic archaeology. In: Hovers E, Kuhn SL (eds) Transitions before the transition: evolution and stability in the middle paleolithic and middle stone Age. Springer US, Boston

Clarke DL (1968) Analytical archaeology. Methuen \& Co, London

Collard M, Shennan SJ (2008) Patterns, process, and parsimony: studying cultural evolution with analytical techniques from evolutionary biology. In: Stark MT, Bowser BJ, Horne L (eds) Cultural transmission and material culture. The University of Tucson Press, Tucson 
Crampton JS (2007) Elliptic Fourier shape analysis of fossil bivalves: some practical considerations. Lethaia 28:179-186

Donahue RE, Fischer A (2015) A late glacial family at Trollesgave, Denmark. J Archaeol Sci 54:313-324

Eerkens JW, Lipo CP (2007) Cultural transmission theory and the archaeological record: providing context to understanding variation and temporal changes in material culture. J Archaeol Res 15:239-274

Eisenmann S, Bánffy E, Van Dommelen P, Hofmann KP, Maran J, Lazaridis I, Mittnik A, Mccormick M, Krause J, Reich D, Stockhammer PW (2018) Reconciling material cultures in archaeology with genetic data: the nomenclature of clusters emerging from archaeogenomic analysis. Sci Rep 8:13003

Furholt M (2014) Upending a 'totality': re-evaluating corded ware variability in late Neolithic Europe. Proc Prehist Soc 80:67-86

Furholt M (2018) Massive migrations? The impact of recent aDNA studies on our view of third millennium Europe. Eur J Archaeol 21:159-191

Gamble CS, Davies W, Pettitt P, Richards M (2005) The archaeological and genetic foundations of the European population during the late glacial: implications for 'agricultural thinking'. Camb Archaeol J 15:193-223

Hagen J (2003) The statistical frame of mind in systematic biology from quantitative zoology to biometry. J Hist Biol 36:353-384

Hewlett B, Cavalli-Sforza LL (1986) Cultural transmission among Aka pygmies. Am Anthropol 88:922-934

Hofmann D (2015) What have genetics ever done for us? The implications of aDNA data for interpreting identity in early Neolithic Central Europe. Eur J Archaeol 18:454-476

Högberg A (2008) Playing with flint: tracing a child's imitation of adult work in a lithic assemblage. J Archaeol Method Th 15:112-131

Horsburgh KA (2018) David Reich's who we are and how we got here: ancient DNA and the new science of the human past. Curr Anthropol 59:656-657

Iovita R (2009) Ontogenetic scaling and lithic systematics: method and application. J Archaeol Sci 36:1447-1457

Iovita R, Tuvi-Arad I, Moncel M-H, Despriée J, Voinchet P, Bahain J-J (2017) High handaxe symmetry at the beginning of the European Acheulian: the data from la Noira (France) in context. PLoS ONE 12:e0177063

Johannsen NN, Larson G, Meltzer DJ, Vander Linden M (2017) A composite window into human history. Science 356:1118

Jordan P (2009) Linking pattern to process in cultural evolution: investigating material culture diversity among the northern Khanty of northwest Siberia. In: Shennan SJ (ed) Pattern and process in cultural evolution. University of California Press, Berkeley

Jordan P (2015) Technology as human social tradition: cultural transmission among Hunter-Gatherers. University of California Press, Oakland

Jordan P, O’Neill S (2010) Untangling cultural inheritance: language diversity and long-house architecture on the Pacific northwest coast. Philos Trans R Soc B 365:3875-3888

Kirch PV (2018) David Reich's who we are and how we got here: ancient DNA and the new science of the human past. Curr Anthropol 59:661-662

Klein RG (2018) David Reich's who we are and how we got here: ancient DNA and the NEw Science of the Human Past. Curr Anthropol 59:658-659

Kobusiewicz M (2009) The Lyngby point as a cultural marker. In: Street M, Barton RNE, Terberger T (eds) Humans, environment and chronology of the late glacial of the North European Plain. Verlag des Römisch-Germanischen Zentralmuseums, Mainz

Kristiansen K (2014) Towards a new paradigm? The Third Science Revolution and its possible consequences in archaeology. Curr Swed Archaeol 22:11-34

Lave J, Wenger E (1991) Situated learning: legitimate peripheral participation. Cambridge University Press, Cambridge

Linderholm A (2018) David Reich's who we are and how we got here: ancient dna and the new science of the human past. Curr Anthropol 59:655-656

Lipo CP, O’Brien MJ, Collard M, Shennan SJ (eds) (2006) Mapping our ancestors. phylogenetic approaches in anthropology and prehistory. AldineTransaction, New Brunswick

Lopes DM (2009) Drawing in a social science: lithic illustration. Perspect Sci $17: 5-25$

Lycett SJ, Shennan SJ (2018) David Clarke's analytical archaeology at 50 World Archaeol 1-11 50:210-220

Mace R, Holden CJ, Shennan SJ (eds) (2005) The evolution of cultural diversity. A phylogenetic approach. UCL Press, London

Macleod N (1999) Generalizing and extending the eigenshape method of shape space visualization and analysis. Paleobiology 25:107-138

Marwick B (2017) Computational reproducibility in archaeological research: basic principles and a case study of their implementation. J Archaeol Method Th 24:424-450

Marwick B, Guedes JDA, Barton CM, Bates LA, Baxter M, Bevan A, Bollwerk EA, Bocinsky RK, Brughmans T, Carter AK, Conrad C, Contreras DA, Costa S, Crema ER, Daggett A, Davies B, Drake BL, Dye TS, France P, Fullagar R, Giusti D, Graham S, Harris MD, Hawks J, Heath S, Huffer D, Kansa EC, Kansa SW, Madsen ME, Melcher J, Negre J, Neiman FD, Opitz R, Orton DC,
Przystupa P, Raviele M, Rielsalvatore J, Riris P, Romanowska I, Smith J, Strupler N, Ullah II, Vlack HGV, Vanvalkenburgh N, Watrall EC, Webster C, Wells J, Winters J, Wren CD (2017) Open science in archaeology. SAA Archaeol Record 17:8-14

Marwick B, Schmidt S (2019) Tool-driven revolutions in archaeological science. https://osf.io/preprints/socarxiv/4nkxv/.

Mathiassen T (1946) En senglacial boplads ved bromme. Aarbøger for nordisk Oldkyndighed og Historie 1946:121-197

Mayr E (1959) Typological versus population thinking. In:Meggers BJ (ed) Evolution and anthropology: a centennial appraisal. The Anthropological Society of Washington, Washington, D.C.

Montelius GOA (1903) Die typologische methode. Almqvist \& Wicksell, Stockholm

O'Brien MJ (ed.) (2008) Cultural transmission and archaeology: issues and case studies. Society for American Archaeology Press, Washington, D.C.

O'Brien MJ, Lyman RL (2000) Applying evolutionary archaeology. a systematic approach. Kluwer Academic/Plenum, New York

O'Brien MJ, Lyman RL, Collard M, Holden CJ, Gray RD, Shennan SJ (2008) Transmission, phylogenetics, and the evolution of cultural diversity. In: O'Brien MJ (ed) Cultural transmission and archaeology: issues and case studies. Society for American Archaeology Press, Washington, DC

O'Hara RJ (1997) Population thinking and tree thinking in systematics. Zool Scr 26:323-329

Petřík J, Sosna D, Prokeš L, Štefanisko D, Galeta P (2018) Shape matters: assessing regional variation of Bell Beaker projectile points in Central Europe using geometric morphometrics. Archaeol Anthrop Sci 10:893-904

Pickrell JK, Pritchard JK (2012) Inference of population splits and mixtures from genome-wide allele frequency data. PLOS Gene t8:e1002967

R CORE T (2017) R: A language and environment for statistical computing. $R$ Foundation for Statistical Computing

Reich D (2018) Who we are and how we got here. Oxford University Press, Oxford Riede F (2006) The Scandinavian connection. The roots of Darwinian thinking in 19th century Scandinavian Archaeology. Bull Hist Archaeol 16:4-19

Riede F (2009a) Tangled trees. Modeling material culture change as host-associate co-speciation. In: Shennan SJ (ed.) Pattern and process in cultural evolution. University of California Press, Berkeley

Riede F (2009b) The loss and re-introduction of bow-and-arrow technology: a case study from the Southern Scandinavian Late Palaeolithic. Lithic Technol 34 (1):27-45

Riede F (2010) Why isn't archaeology (more) Darwinian? A historical perspective. J Evol Psychol 8:183-204

Riede F (2011a) Adaptation and niche construction in human prehistory: a case study from the southern Scandinavian Late Glacial. Phil Trans R Soc B 366:793-808

Riede F (2011b) Steps towards operationalising an evolutionary archaeological definition of culture. In: Roberts BW, Vander Linden M (eds) Investigating archaeological cultures. material culture, variability, and transmission. Springer, New York

Riede F (2017) The 'Bromme problem'-notes on understanding the Federmessergruppen and Bromme culture occupation in southern Scandinavia during the Allerød and early Younger Dryas chronozones. In: Sørensen M, Buck Pedersen K (eds) Problems in palaeolithic and mesolithic research. University of Copenhagen and Museum of Southeast Denmark, Copenhagen

Roberts BW, Vander Linden M (2011) Investigating archaeological cultures: material culture, variability, and transmission. In: Roberts BW, Vander Linden M (eds.) Investigating archaeological cultures. Material culture, variability, and transmission. Springer, New York

Rogers DF, FOG NR (1989) Constrained B-spline curve and surface fitting. Comput-Aided Des 21:641-648

Rohlf FJ (2015) The Tps Series of Software Hystrix 26:9-12. https://doi.org/ 10.4404/hystrix-26.1-11264

Rohlf FJ, Archie JW (1984) A comparison of fourier methods for the description of wing shape in Mosquitoes (Diptera: Culicidae). Syst Biol 33:302-317

Sackett JR (1991) Straight archaeology French Style: the phylogenetic paradigm in historic perspective. In: Clark GA (ed.) Perspectives on the Past. Theoretical Biases in Mediterranean Hunter-Gatherer Research. University of Pennsylvania Press, Philadelphia

Saragusti I, Karasik A, Sharon I, Smilansky U (2005) Quantitative analysis of shape attributes based on contours and section profiles in artifact analysis. J Archaeol Sci 32:841-853

Sauer F, Riede F (2019) A critical reassessment of cultural taxonomies in the Central European Late Palaeolithic. J Archaeol Method Th 26:155-84

Schillinger K, Mesoudi A, Lycett SJ (2016) Copying error, evolution, and phylogenetic signal in artifactual traditions: an experimental approach using "model artifacts". J Archaeol Sci 70:23-34

Serwatka K (2015) Bifaces in plain sight: testing elliptical fourier analysis in identifying reduction effects on Late Middle Palaeolithic bifacial tools. Litikum 3:13-25 
Serwatka K, Riede F (2016) 2D geometric morphometric analysis casts doubt on the validity of large tanged points as cultural markers in the European Final Palaeolithic. J Archaeol Sci 9:150-159

Shennan SJ (2002a) Archaeology evolving: history, adaptation, self-organization. Antiquity 76:253-256

Shennan SJ (2002b) Genes, memes and human history: Darwinian archaeology and cultural evolution. Thames and Hudson, London

Shennan SJ (2004) Analytical archaeology. In: Bintliff JL (ed.) A companion to archaeology. Blackwell, Oxford

Shennan SJ (2008) Evolution in archaeology. Ann Rev Anthropol 37:75-91

Shennan SJ (ed.) (2009) Pattern and process in cultural evolution. University of California Press, Berkeley

Shennan SJ (2011) Descent with modification and the archaeological record. Philos Trans R Soc B 366:1070-1079

Shennan SJ, Crema ER, Kerig T (2015) Isolation-by-distance, homophily, and "core" vs. "package" cultural evolution models in Neolithic Europe. Evol Hum Behav 36:103-109

Sinitsyna G (2002) Lyngby points in eastern Europe. Archeol Baltica 5:83-93

Stark MT, Bowser BJ, Horne L (eds) (2008) Cultural transmission and material culture. The University of Tucson Press, Tucson

Szymczak K (1987) Perstunian culture-the eastern equivalent of the Lyngby culture in the Neman Basin. In: Burdukiewicz JM, Kobusiewicz M (eds) Late Glacial in central Europe: culture and environment. Polskiej Akademii Nauk, Wrocław

Tehrani JJ, Collard M, Shennan SJ (2010) The cophylogeny of populations and cultures: reconstructing the evolution of Iranian tribal craft traditions using trees and jungles. Phil Trans R Soc B 365:3865-3874

Tehrani JJ, Riede F (2008) Towards an archaeology of pedagogy: learning, teaching and the generation of material culture traditions. World Archaeol 40:316-331

Tostevin GB (2013) Seeing lithics: a middle-range theory for testing for cultural transmission in the Pleistocene. Oxbow Books, Oxford

Trigger B (2006) A history of archaeological thought. Cambridge University Press, Cambridge

Vander Linden M (2016) Population history in third-millennium-BC Europe: assessing the contribution of genetics World Archaeol 1-15 48:714-728

Vander Linden M (2018) David Reich's who we are and how we got here: ancient DNA and the new science of the human past. Curr Anthropol 59:657-658
Yu G, Smith DK, Zhu H, Guan Y, Lam TT-Y (2016) ggtree: an R package for visualization and annotation of phylogenetic trees with their covariates and other associated data. Methods Ecol Evol 8:28-36

Zahn CT, Roskies RZ (1972) Fourier descriptors for plane closed curves. IEEE Trans Comput C-21:269-281

\section{Acknowledgements}

FR and CSH thank the Independent Research Fund Denmark for grant \#610700059B and FR also gratefully acknowledges funding from the European Research Council (Consolidator Grant grant agreement 817564 under the Horizon 2020 research and innovation programme).

\section{Additional information}

Competing interests: The authors declare no competing interests.

Reprints and permission information is available online at http://www.nature.com/ reprints

Publisher's note: Springer Nature remains neutral with regard to jurisdictional claims in published maps and institutional affiliations.

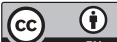

Open Access This article is licensed under a Creative Commons Attribution 4.0 International License, which permits use, sharing, adaptation, distribution and reproduction in any medium or format, as long as you give appropriate credit to the original author(s) and the source, provide a link to the Creative Commons license, and indicate if changes were made. The images or other third party material in this article are included in the article's Creative Commons license, unless indicated otherwise in a credit line to the material. If material is not included in the article's Creative Commons license and your intended use is not permitted by statutory regulation or exceeds the permitted use, you will need to obtain permission directly from the copyright holder. To view a copy of this license, visit http://creativecommons.org/ licenses/by/4.0/

(C) The Author(s) 2019 